chloroform to a casual patient sitting in a dentist's chair is not only most incxpedient but is highly dangerous.ED. L.

\section{"THE DIAGNOSIS OF TONSILLITIS."}

\section{To the Editors of THE LANCET.}

SrRs,-Under the above heading, with reference to certain "cases in the parish of Fulham very like diphtheria in its early stage," Dr. Robert Lee states: "We have reasons for knowing that, although the Klebs-Löffler microbes may be present, this disease is not diphtheria." It would be conducive to a much clearer understanding if Dr. Lee would tell us what those reasons may be.

I am, Sirs, yours truly,

ARTHUR H. W. Cremow, M.D. Edin.

Earl's-court-road, Kensington, Dec. 3rd, 1895.

\section{THE CASE OF DR. WIGHT.}

\section{To the Editors of THE LANCET.}

SIns, - The jury have found Dr. Wight guilty of the offence with which he was charged; but, after all, a jury composed of laymen must, even with the assistance of the evidence of medical experts, have great difficulty in coming to a just conclusion. They, no doubt, do their best in such cases, and no doubt they did their best in this case to master the questions submitted to them. Still, there are medical aspects of the question which they must find it almost impossible to appreciate. For example, rupture of the uterus in its most complete form may occur in the course of the operation of version, no matter how carefully performed, and no matter whether the operator merely be one of whom the ordinary degree of skill may be expected, or whether he be one of special skill and experience in the performance of obstetric operations. The same is true as regards cases in which the forceps is used. No doubt such an accident is of great rarity if care and skill be employed; nevertheless, in justice to Dr. Wight, it ought to have been clearly understood that such an accident may happen even in the presence of the highest skill and of the greatest experience. Further than that, in very rare cases rupture of the uterus may occur, not only apart from any operative interference, but apart from any known indication for operative interference. I have in mind such a case. The patient had had two children naturally before and was again in labour. There was no contraction of the pelvis, she had only been in labour some two hours, and the second stage of labour was well advanced, the os uteri being fully dilated, and everything apparently progressing easily and satisfactorily. Suddenly the patient became collapsed; she was then delivered easily with the forceps, but she died in about a quarter of an hour. The child was not unusually large. Post-mortem examination showed that a spontaneous partial rupture of the uterus had occurred under the peritoneum, with extravasation of blood rather low on the posterior wall; the peritoneal coat had then given way over the extravasated blood, and the patient had bled freely into the peritoneum, and so died of hæmorrhage. Had the forceps been used here before the collapse set in it might easily have been suggested that the fatal accident was clue to the unskilful use of the instrument. The case was, in fact, an example of one of those unavoidable accidents that no amount of skill, so far as our present knowledge goes, can foresee or prevent. The possibility that Dr. Wight's patient may have died through the occurrence of an unfortunate accident in a category similar to that of the caso briefly alluded to appears by no means improbable, and, at all events, he seems entitled to the benefit of the doubt, which it is almost impossible to satisfactorily eliminate.

\section{I am, Sirs, yours faithfully,}

Volunteer Ambulance School of InstrucTION.-We are asked to state that, owing to want of room, the honorary secretaries are unable to issue any more tickets for the concert and distribution of prizes of the Volunteer Ambulance School of Instruction, which will take place at Crosby Hall to-day (Saturday).

\section{THE BATTLE OF THE CLUBS. (From OUR SPECIAL COMMISSIONER.) (Continued from p. 1327.)}

\section{Unity and Phact at York: a Defence of the}

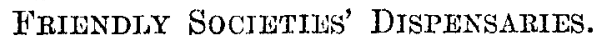

York is the first town I have visited where I have found no. grievance and heard no complaints. The medical profession is absolutely unitcd. The club medical officers hold an. honoured position in the Medical Society. There is no complaint against them; all work harmoniously together. The profession looks upon the friendly societies' dispensary with no unfriendly feeling, and the general impression is that everything is for the best, if not in the best of possible worlds, at least in York, which is evidently, so far as professional interests are concerned, the best of possible towns. Not a little of this very exceptional contentment is due to the early organisation of the profession. The record carefully kept states. that on Feb. 18th, 1832, a meeting of medical men was held in the house of Dr. Goldie in York. Dr. Wake was in the chair, and it was then decided to issue a circular inviting"physicians and members of the Association of SurgeonApothecaries resident in York" to form a medical society. The first meeting was held on the following March 3rd, and: then the York Medical Society was formally constituted. From the very first the society displayed great activity. It held meetings at the dispensary on every alternate Saturday evening during the session. This continued till 1859, when a special room was rented in Marketstreet. The meetings were held there until the year 1874, and during the following three years in the boardroom of the York County Hospital. After this the society removed to a more central part of the city, and finally, in 1890, a permanent library and meeting room was rented and furnished at Low Ousegate. The objects of this society are "the advancement and diffusion of medical knowledge." The membership is limited to duly qualified medical practitioners. The subscription is one guinea per annum for town members residing within three miles of the General Post Office, York, and half that sum for county members residing beyond this distance. A single payment of $£ 55$ s. constitutes a life membership. The society holds every year twelve ordinary meetings during the session, which begins in October. The reading room is open from 10 A.M. to 10 P.M., and a sum is annually voted for the purchase of books and instruments. The members may borrow and use these instruments, but are fined if the instruments are detained beyond a reasonable time or are not returned clean and in good condition. All the practitioners at York have joined this association. Now in the constitution of this society there are two features which hare a practical bearing on the question of the clubs. From the very first, not only have the club physicians been admitted, but a special point has been made of gaining their adhesion. More than this, Mr. Bryson, the principal medical officer of the friendly societies' dispensary, has been elected a member of the council of the York Medical Society. Secondly, it will be noted that the society holds frequent meetings; thus the medical men are kept well in touch, and are therefore more likely to act loyally towards each other. Differences which are so often due to a want of mutual understanding may thus be explained away before they have time to reach an acute stage.

Both Dr. James Ramsay, the president, and Dr. Richard Turner, the secretary of the society, assured me that the medical officers in the service of the friendly societies were most honourable men, against whom there was no sort of complaint, and with whom they had frequent consultations. Little or no difficulty had arisen with regard to infectious cases and the notification of such cases. The club medical men had, in all circumstances, supported the York Medical Society. Dr. Ramsay, on his side, always refused to attend members of the friendly societies unless in consultation, in order to show club patients that they could not do just as they liked. If people join a club, then they must adhere to the medical officer of the club, and not call in a private practitioner to make up for any shortcoming that may arise in the club method of treatment. Dr. Ramsay, however, far from feeling any resentment against these clubs, thought that the medical profession had, 